rare combination of Helen Haines and R. R. Hawkins, with some traces of Besterman. All frivolity aside, these papers provide substance for future planning.

The remaining papers touch on specialized types of public and peripheral types of material. In William S. Budington's "Problems of Selection in Science" one can readily sense the particular public of a John Crerar type of library. "The Components of the Science Collection" reflects accurately in its enumeration of types of materials the long experience of Irene Strieby in special libraries and their needs. The brief sketch of "Science Fiction as Literature" is lesser fillip, the frosting on the cake, bringing this collection to its conclusion, succinctly outlined by Harold Lancour with his customary Gallic humor. The conclusion, that "Science belongs in every library", and "Librarians will need, in the immediate years ahead, to inform themselves as never before about the world of science," is not itself news or a great contribution. A considerable contribution has been made, however, in adding to library literature an up-to-date, authoritive handbook to enable those less knowledgeable in the sciences to cope with the needs of our changing public.-Jerrold Orne, University of North Carolina.

\section{Circulation Systems}

Study of Circulation Control Systems. George Fry \& Associates, Inc. (Library Technology Project Publications, number I) Chicago: Library Technology Project of the American Library Association, 1961. 138p. \$2.50.

This attractively designed workbook is the end result of a long-awaited and comprehensively carried out study of circulation systems by a private management group in cooperation with an advisory committee of librarians. It is also the first publication to appear under the aegis of the Library Technology Project. The final product contains three manuals with tear-away worksheets for comparing systems in use, plus a truly impressive amount of statistical data.
George Fry \& Associates, management consultants, were commissioned for this detailed analysis of circulation in the field by the Council on Library Resources in cooperation with the Library Technology Project of the American Library Association and the Special Libraries Association. Limited in scope to only the operations of borrower registration, charging and discharging of books, handling overdues and reserves, and circulation statistics, the study also involved sending some 4,585 questionnaires to varied libraries. Three hundred and thirty-one of these went to college and university libraries. These questionnaire results are tabulated in the study. During the actual study, seventy-three public libraries were visited, along with nineteen college and university libraries and twelve special libraries.

Actually, the report, conceived as a "guide in hand" for administrators instituting or revising present circulation systems, is divided roughly into two halves. The first covers the procedures under which the study was conducted, together with a review of current circulation control practices and recommendations as to modifications and improvement. The second (and larger half) consists of the three manuals, complete with indented, numbered tabs, provided procedural and cost information on the leading circulation control systems and their variations for public, college and university, and special libraries. The practical core of each manual is a number of blank work sheets, with accompanying explanatory samples, intended to be filled out when studying one's own needs with a view to estimating costs, modification, or consideration of a new system. The entire report is bound in plastic spiral so that these work sheets, one to be used for studying each charging point in the library, may be easily removed.

Both the Council on Library Resources and LTP are to be commended for their foresight in initiating this project and in providing the wealth of comparative information brought forth. This reviewer was intrigued by probable uses of the work sheets, although broad use and reports of resulting savings and modifications will necessarily first have to be evaluated for full practical evidence. Nevertheless, it is reassuring to see the potentials of management analysis ap- 
plied to this traditional, and ofttimes neglected, problem area of libraries.

Specifically, the statistical Exhibit 1V-B will be of immediate interest to circulation personnel with its provision of a percentile chart on "Elemental Times for College and University Library Circulation Systems," as will be the other exhibits on equipment and material costs. Such gatherings of cost data have been needed for years. Also, in Chapter 5 of the report, "Future Mechanization," the administrator can speculate on an "ideal" circulation system of the future.

One disappointing note is found, however. Despite the excellence of charts, graphs, and data, the findings reported in the narrative portion of the study will be found somewhat elementary by the experienced circulation librarian or administrator alert to public service functions. In fairness it must be said that the Fry organization had to begin this study as a complete stranger to the field. Their representatives, to become familiar with nomenclature and work methods, visited fifty libraries, interviewing, filming operations, and conducting preliminary time and motion studies. However, despite the desirability of a fresh viewpoint, there is room here to wonder whether such a study done by experienced librarians, paid and on leave, might not have accomplished similar results without such time lost in preparation and familiarization.

While this study should be of solid assistance in system revision and improvement, and while it reports concisely on twenty-eight charging systems now in use, it is regretted that one or two newer circulation modifications in the field were also not reported on. Reference is made to the Bookamatic modification now in operation at the Princeton University Library, which significantly reduces the high costs of Bookamatic reported in the Fry study, and in the earlier Diebold study. This modification eliminates both the costly, little-used Bookamatic multiple form and plastic book card, and by means of a plastic campus identification card and a redesigned imprinter, permits imprinting of any library's regular bookcards. -Warren B. Kuhn, Princeton University Library.

\section{Two Outstanding Bibliographies}

\section{And Art References}

\section{Edward Lear on My Shelves}

Including: Biography of Lear; Published Works; Diaries; List of Original Drawings and Water Colors; List of Lithographs, Engravings and Woodcuts. 455 pages; 453 beautiful illustrations. 1933

Price only $\$ 45.00$ net

\section{John Leech on My Shelves}

Including a Short Biography; Bibliography of Illustrated Books; Leechiana; Original Drawings and Sketches; List of Etchings and Woodcuts; List of Reference Books.

313 pages; 303 beautiful illustrations. 1930

Price only $\$ 45.00$ net

\section{Both by William B. Osgood Field}

Privately printed at the Bremer Press, Munich, each limited to 155 Signed Copies. Both volumes are uniform, measuring $91 / 2^{\prime \prime}$ wide by $131 / 2$ " tall, bound in blue boards, cloth backs and individually slipcased.

These are magnificent examples of exhaustive bibliographic research and superb specimens of book making art by one of the world's finest presses. They are essential additions to complete Art and Bibliography collections.

\section{Ira J. Friedman, Inc. \\ Booksellers-Publishers-Importers \\ Port Washington, L. I., N. Y.}

